\title{
Beyond constituency tests: A reply to Osborne
}

\author{
Matthew Reeve ${ }^{\mathrm{a}}$ \\ a School of International Studies, Zhejiang University, mjreeve@zju.edu.cn.
}

\begin{abstract}
Timothy Osborne argues that phrase structure grammars (PSGs) postulate unnecessarily complex structures, and that Dependency Grammar (DG) is to be preferred on grounds of simplicity (1:1 word-to-node ratio) and empirical adequacy (capturing the results of constituency tests). In this reply, I argue that, while some of Osborne's criticisms of PSGs are justified, there are both empirical and theoretical problems with his major claims. In particular, his version of DG is too restrictive with respect to certain constituency facts (modified nouns, verbal phrases), and what it gains in simplicity qua number of nodes, it loses in requiring a more complex interface between syntax and other linguistic components (phonology, semantics). I argue that Mirror Theory, a framework that is in a sense intermediate between DG and PSGs, answers Osborne's justified criticisms while not suffering from the problems of his version of DG.
\end{abstract}

Keywords: Dependency Grammar, Minimalism, Mirror Theory, constituency test, head, verb phrase, adverb

\section{Introduction}

Osborne (2018) argues that syntactic frameworks based on phrase structure, such as Chomskyan Minimalism, postulate unnecessarily complex structures, and that Dependency Grammar (DG) is to be preferred on both theoretical and empirical grounds: theoretically because of its maximally simple 1:1 word-to-node ratio, and empirically because it captures the results of constituency tests better than phrase structure grammars (PSGs). A key assumption lying behind Osborne's remarks is that the results of constituency tests can decide between rival syntactic frameworks regardless of other possible reasons for postulating relatively complex structures. I will argue that, while some of Osborne's criticisms are justified, his reply overlooks

Language Under Discussion, Vol. 5, Issue 1 (April 2018), pp. 68-82

Published by the Language Under Discussion Society

This work is licensed under a Creative Commons Attribution 4.0 License. 
the trade-off between the relative complexity of the syntactic structures posited by PSGs and the relative simplicity of the phonological and semantic interpretation of these structures. I will argue that Mirror Theory (MT; Brody 2000a, 2000b, 2003), an offshoot of Minimalism that approaches DG in certain respects, answers most of the challenges that Osborne poses for PSGs, while still enabling a relatively simple interface between syntax and phonological/semantic interpretation.

Section 2 briefly introduces MT, noting the key similarities and differences between MT, Osborne's variant of DG (henceforth O-DG), and PSGs (head/phrase distinction; word-node ratio; number of daughters). Section 3 argues that Osborne is correct in identifying certain heads (transitive verbs, auxiliaries) as non-constituents, but that O-DG (but not MT) is too restrictive with respect to modified nouns, which behave like constituents. Section 4 argues that Osborne's use of constituency tests as necessary (rather than sufficient) conditions for constituency is too strict, in particular with respect to verbal phrasal constituents. Section 5 argues that the 1:1 word-node ratio of O-DG creates complications for the interface between syntax and other components of the language faculty (phonology, semantics), focusing in particular on the ordering and scope of adverbial and verbal elements. I argue that the relaxation of the 1:1 ratio in MT and PSGs is compensated for by a simpler interface relation as compared with O-DG.

\section{Mirror Theory}

Although one could get the impression from Osborne's paper that the central debate is between dependency-based and constituency-based frameworks, this is not quite true. Osborne's variant of DG also makes crucial use of the notion of constituent, in that respect departing from most DG frameworks, as he himself notes. The central question, then, is really how many constituents there are in a given sentence.

I believe that Osborne is partly correct in his claim that the head-phrase distinction posited within PSGs is unnecessary. In fact, this kind of argument has also been made within the generative literature, though for different reasons, by Brody (2000a, 2000b, 2003) and Bury (2003), among others. In this discussion note, I will argue that the framework proposed in Brody's work, Mirror Theory (MT), can answer the criticisms posed by Osborne, while preserving the desirable aspects of Minimalist PSG work (essentially the framework deriving from Chomsky 1995, 2000, 2001, with accessible introductions including Adger 2003 and Hornstein et al. 2005).

MT is particularly interesting in that it is in a sense intermediate between Minimalism and DG. On the one hand, it is like O-DG in that it rejects the distinction between heads and phrases (a property Brody 2000a, 2000b refers to as Telescope), and allows spell-out of non-terminal nodes. On the other hand, MT is like Minimalism, and unlike O-DG, in postulating a relatively 'abstract' syntactic structure in which the number of nodes is normally larger than the number of words, and in adopting a maximally binary-branching structure (i.e., a mother node has no more than two daughter nodes). ${ }^{1}$ The key motivation behind MT is to account for what Brody (2000a) calls the 'mirror generalisation' (see, e.g., Baker 1985, Cinque 1999, Adger et al. 2009). In

\footnotetext{
${ }^{1}$ As Brody (2000a: 41) puts it, “Telescope can be viewed as eliminating the apparent conflict between the long tradition of dependency theories (see, e.g., Hudson 1990 and references cited there) and phrase structure theories of syntactic representations." Brody also cites Brody (1994) and Manzini (1995) as "recent attempts to simplify the theory of phrase structure in terms of dependencies" (Brody 2000a: $41 \mathrm{fn} .10$ ).
} 
the form that Brody adopts (see also Cinque 1999), the mirror generalisation amounts to the claim that morphological suffixes appear in the opposite order to their equivalent syntactic heads (i.e., independent words). To take a relatively simple example, Cinque (1999: 198 fn. 2) suggests that Hawick Scots 'double modal' sentences such as (1a) have their "exact mirror image" in Turkish, as seen in (1b):

(1) a. He'll might could do it for you. (Cinque 1999: 79)

he.FUT POSSIB ABIL do it for you

'He might be able to do it for you.'

b. Gel-e-me-yebil-ecek. (ibid.: 198 fn. 2)

come-ABIL-NEG-POSSIB-FUT

'(S)he may in the future not be able to come.'

In Hawick Scots, future tense, epistemic modality, negation and deontic/dynamic modality are expressed by independent words preceding the main verb. By contrast, in Turkish these categories are expressed by verbal suffixes appearing in the reverse linear order of the Scots equivalents.

The basic structural principle of MT can be illustrated by comparing the tree in (2a), which depicts the general 'X-bar' structure of phrases in PSGs, with the equivalent MT tree in (2b). In (2a), XP represents the whole phrase, headed by X, ZP is a phrase that functions as the 'specifier' of XP, and YP is a phrase that functions as the 'complement' of X. For example, in earlier analyses of the noun phrase Noam Chomsky's theories of grammar (e.g., Chomsky 1970), theories would be the head, Noam Chomsky's (a distinct NP) the specifier, and of grammar (a prepositional phrase) the complement. By contrast, the equivalent MT tree in (2b) simplifies the structure by abolishing the ' $\mathrm{XP}$ ' and ' $\mathrm{X}$ ' levels; here, $\mathrm{X}$ corresponds to the head, $\mathrm{Z}$ is its specifier and $\mathrm{Y}$ is its complement (see Brody 2000a: 40):

(2) a

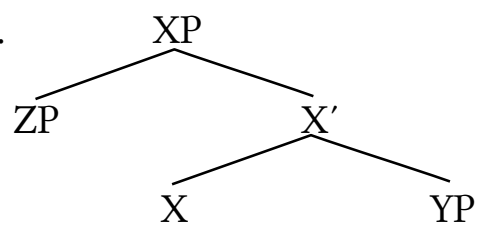

b.

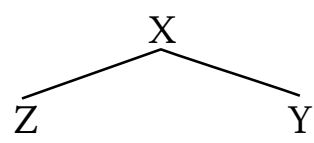

The relation between $\mathrm{X}$ and its specifier can be seen as parallel to the relation between a head and its dependent in O-DG; here, $\mathrm{Z}$ is an independent word or phrase that is grammatically dependent on $\mathrm{X}$ (e.g., the object of a lexical verb). The relation between $\mathrm{X}$ and its complement also represents a dependency, but one that is expressed in terms of inflectional morphology. A further important aspect of the tree in $(2 b)$ is the claim that a specifier always precedes its head, and a head precedes its complement (following Kayne 1994). ${ }^{2}$ For Brody, $\mathrm{Z}$ is a syntactic

${ }^{2}$ Inflectional suffixation is overwhelmingly preferred over inflectional prefixation in the world's languages. For example, Dryer (2013) gives 406 languages as "predominantly suffixing" and 123 as having a "moderate preference for suffixing", as against 58 that are "predominantly prefixing" and 94 having a "moderate preference for prefixing". While the directionality of this tendency is as expected under the mirror generalisation (cf. Svenonius 2016: 211), the existence (in fact, non-rarity) of inflectional prefixation still needs to be explained. MT must either reanalyse inflectional prefixes as independent words or claim that Mirror does not apply systematically (cf. Brody 2000a: 34), but discussion of this issue would take us too far afield. 
specifier of $\mathrm{X}$, and hence $\mathrm{Z}$ precedes $\mathrm{Y} / \mathrm{X}$. On the other hand, the syntactic complement relation also represents a 'morphological specifier' relation 'in reverse'. That is, $\mathrm{Y}$ and $\mathrm{X}$ form a single word in which $\mathrm{Y}$ is a morphological specifier of $\mathrm{X}$, so $\mathrm{Y}$ precedes $\mathrm{X}$. For example, the structure of Noam Chomsky's theories of grammar might be represented in MT as in (3b), corresponding to the more recent Minimalist PSG analysis in (3a):

(3) a

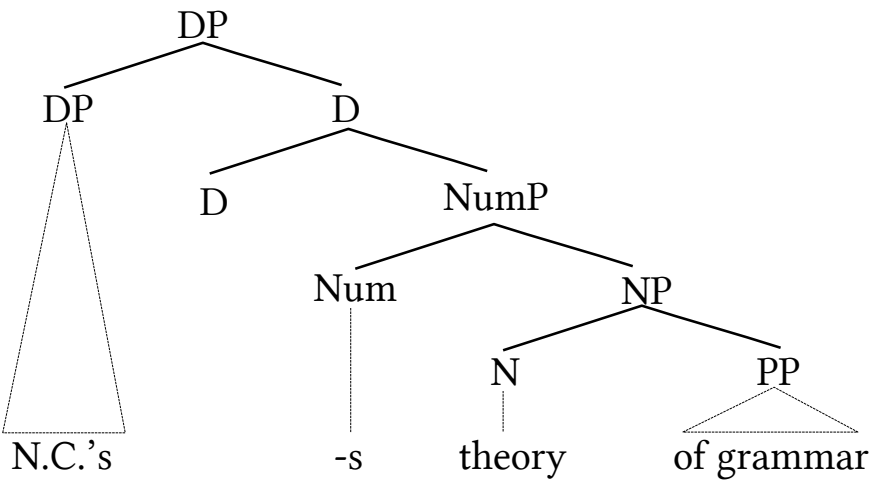

b.

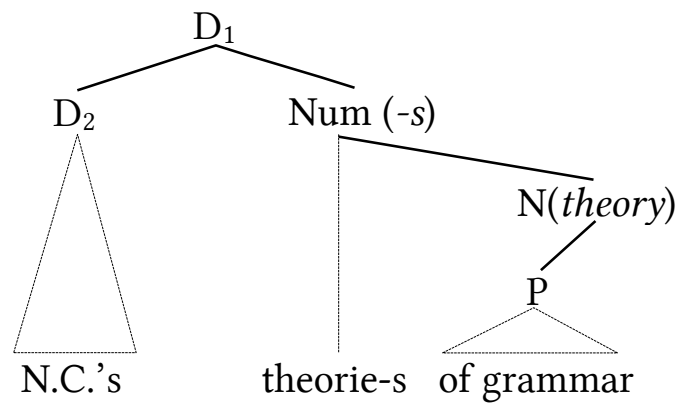

In (3a), the noun theory is normally taken to be combined with the plural affix either through $\mathrm{N}$ 'raising' to Num, or through Num 'lowering' to N. In (3b), by contrast, the word is directly 'read' off the tree from bottom to top: the noun $(\mathrm{N})$ theory is a morphological specifier of the affix in Num, and hence N precedes Num. There is then a choice - fixed for a particular language - to pronounce the noun (plus any affixes) either in the $\mathrm{N}$ node or in the Num node. If it is pronounced in $\mathrm{N}$, then it follows its complement (of grammar), as in Mandarin Chinese guānyú yǔfă de lìlùn (lit. 'about grammar LINKER theory'). If it is pronounced in Num, then it precedes its complement, resulting in 'head-initial' word order, as in English.

As the remainder of my discussion note will focus on the structure of the clause, let us now consider how this is represented in the three approaches. For example, the MT-style analysis of the sentence fohn writes poems is given in (4) (I ignore the question of whether the subject and object have internal structure):

(4)

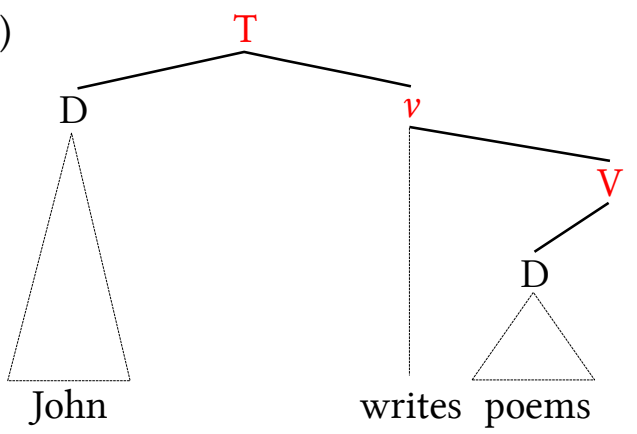


Here, the -s suffix, representing $\mathrm{T}(\mathrm{ense})$, forms a morphological word with the main verb, in contrast to cases in which an auxiliary represents $\mathrm{T}$ (e.g., He will write poems), in which case the auxiliary precedes the main verb. In (4), the verb is the morphological specifier of a functional category $v$ ('little V'), which itself is the morphological specifier of T. ${ }^{3}$ This means that the verb's morphological word (represented by the nodes in red in the tree) is pronounced in the order write> $v>-s$. In English, the chosen node for pronouncing the verb plus its affix is $v$; because $\mathrm{V}$ is the complement of $v$, this means that writes precedes poems. In OV languages such as Hindi-Urdu, the verb plus any affixes is pronounced in V; as poems is the specifier of $\mathrm{V}$, this results in the order poems $>$ writes.

If (4) is compared with the Minimalist-type analysis in (5a) and the O-DG analysis in (5b), it will be clear that MT has commonalities with both approaches:

(5) a.

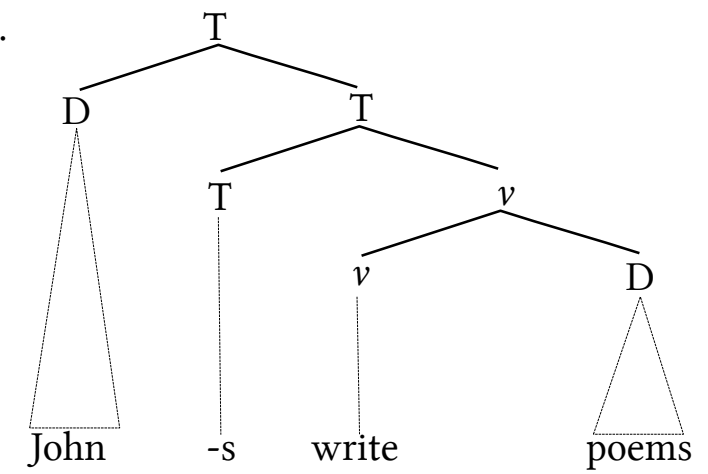

b.

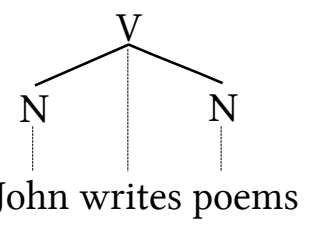

(5a) differs from (4) in that only 'terminal nodes' (nodes that dominate no other nodes) are pronounced, and in the notion of categorial projection (e.g., the verb forms a verb phrase with its sister node in the tree). In these respects, MT is like O-DG. (5a) and (4) are similar, however, in that the tense/agreement suffix $-s$ spelled out on the verb corresponds to a distinct syntactic node, $\mathrm{T}$ (ense). ${ }^{4}$ That is, the word-to-node ratio is not 1:1, in contrast to O-DG.

In the following sections, I will argue that MT is not subject to the (justified) criticisms that Osborne levels at PSGs, but has advantages over O-DG in its ability to handle certain constituency and ordering facts that Osborne does not discuss. I begin by examining Osborne's claim that heads (in the PSG sense) may be non-constituents.

\footnotetext{
${ }^{3}$ The category $v$ is a 'light verb' that originates in Chomsky (1995) and Kratzer (1996). While $v$ does not correspond to a pronounced morpheme in this sentence, it has been argued that the do of do so (Fohn must do so) and British English do (Fohn must do) are realisations of $v$ (see Haddican 2007 and references cited there).

${ }^{4}$ As for how the verb is combined with its suffix, it is normally assumed either that the verb 'moves to T' (e.g., Chomsky 1995) or that the two are combined in the morphological component of the grammar (e.g., Bobaljik 1995).
} 


\section{Heads as non-constituents}

Because it is like O-DG in (largely) abolishing the head-phrase distinction, MT can account for Osborne's evidence against treating transitive verbs and auxiliaries as constituents; for example, the fact that they cannot undergo topicalisation:

(6) a. ... and show syntactic structure, trees CAN. ${ }^{5}$

b. *... and show, trees can syntactic structure.

c. *...and can trees show syntactic structure. [declarative]

Just as in the O-DG tree, the auxiliary and verb in the MT tree do not correspond to constituents.

The situation is slightly different in the case of nouns modified by a determiner or an adjective, which Osborne also claims should not be constituents. He uses the following examples to support this claim:

(7) a. Syntactic structure, trees can show.

b. *Structure, trees can show syntactic.

While the noun phrase as a whole can be topicalised, the noun alone cannot. While it is indisputable that topicalisation fails to identify the noun as a constituent, the fragment answer test contradicts this result. In response to an 'echo' wh-question, for example, the noun alone can be used as a fragment answer, as in (8a). Contrast this with (8b), in which the same is attempted with a verb, but the result is very unnatural: 6

(8) a. This test probes syntactic WHAT? STRUCTURE.

b. This test does WHAT to syntactic structure? \#PROBES. / PROBES it.

This fact is problematic for the O-DG analysis, under which the noun could not be a constituent here, as it dominates the adjective that modifies it. ${ }^{7}$ Whether the same problem holds for MT depends on how modification should be treated. I will assume, as was standard within earlier generative work (e.g., in the Government-Binding tradition following Chomsky 1981), that modifiers are introduced by 'adjunction', an operation that creates an extra node of the same label as the modified category. ${ }^{8}$ An adjunction analysis correctly predicts that the noun can be

${ }^{5} \mathrm{Can}$ in (6a) is in all-capitals to indicate that topicalisation here requires main stress to fall on the auxiliary.

${ }^{6}$ Sergeiy Sandler (p.c.) suggests that the following dialogue is also possible:

(i) A: This test WHAT syntactic structure?

B: PROBES.

Although this seems ill-formed to me, if there are speakers who find it acceptable, this is problematic for O-DG in the same way that $(8 \mathrm{a})$ is.

${ }^{7}$ It is also problematic for approaches that seek to equate the set of possible fragments with the set of constituents that can undergo movement (e.g., Merchant 2004). See also Culicover \& Jackendoff (2006) for criticism of this approach.

${ }^{8}$ Bury (2003) adopts a similar view in an MT-related framework (see also Uchida \& Bury 2008, Bury \& Uchida 2012). This is different from the treatment of modifiers in 'standard' MT (e.g., Brody 2000a: 53, 2003, Brody \& Szabolcsi 2003: 37, Adger et al. 2009, Adger 2013), but the choice between these analyses does not affect the argumentation here. 
treated as a constituent. ${ }^{9}$ Such an analysis, however, is incompatible with the basic tenets of ODG, as it entails giving up the 1:1 word-to-node ratio. If they are taken to be necessary conditions for constituency, then, constituency tests cut both ways: they are problematic for ODG as well as for MT and standard Minimalism. In the next section, I will examine another such case, concerning the question of which verbal phrasal constituents are identified by constituency tests.

\section{Finite VPs as constituents?}

As Osborne has emphasised in other work (esp. Osborne \& Gross 2016), an O-DG analysis entails that there is no such thing as a tensed or finite verb phrase (VP) constituent, as is clear from the tree in (5b). By contrast, in Minimalism the tensed verb and its object must correspond to a constituent (whether or not this is a VP) excluding the subject, as seen in (5a). As for MT, although the tree in (4) represents the affix $-s$ in the T node dominating the subject, it is assumed that it is ultimately spelled out in $v$ along with the verb, and hence that in some sense there is a finite $\mathrm{VP}(v \mathrm{P})$ constituent.

Although Osborne does not discuss this difference in detail in the target paper (Osborne 2018), he provides examples such as (9) to support the claim that the tensed auxiliary does not form a constituent with its dependents:

(9) a. *...and can show syntactic structure, trees.

b. *What trees do is can show syntactic structure.

c. ${ }^{*}$ What can trees do? Can show syntactic structure.

Again, the results of these tests are indisputable, and it is true that O-DG predicts this as a matter of principle, while it is less clear that this is the case for Minimalism and MT. Yet the problem of what kinds of verbal strings pass these tests is broader than Osborne acknowledges. For example, some non-finite auxiliary phrases do not pass any of the tests (Pullum \& Wilson 1977), despite indisputably being constituents under an O-DG (or Minimalist or MT) analysis: ${ }^{10}$

(10) a. * Have been being eaten, the banana must.

b. *Been being eaten, the banana must have.

c. Being eaten, the banana must have been.

d. *Eaten, the banana must have been being.

${ }^{9}$ As for why topicalisation fails, it is an old observation that extraction from noun phrases, even of constituents, is highly restricted (see Reeve 2019 and references cited there).

${ }^{10}$ There are also 'intermediate' cases such as (i), in which the 'raising infinitive' to avoid syntax is a constituent under anyone's approach, but does not pass most of the tests:

(i) a. *To avoid syntax, Bill seems.

b. ?What Bill seems to do is to avoid syntax.

c. *?What does Bill seem to do? To avoid syntax.

d. *It is to avoid syntax that Bill seems. 
It therefore seems unsatisfactory to attribute the failure of the tests in (9) purely to syntactic constituency without providing a reason why the tests also fail in (10). At the very least, such an argument ought to clarify why these phenomena should be treated differently.

In fact, the constituency tests are not even consistent in ruling out a finite VP constituent, as finite VP fragment answers are perfectly acceptable (see Culicover \& Jackendoff 2006 for further divergences between the fragment answer and movement tests):

(11) A: He did WHAT?

B: Threw away Mary's present.

A potential objection is that that B's response involves not a VP fragment answer, but an instance of 'topic drop', a phenomenon known to occur in English (e.g., Haegeman 1990). I think this analysis is doubtful, however, given that a finite VP answer does not seem very good when the context makes fohn a topic, but does not introduce a 'question under discussion' for which a finite VP would be an appropriate answer:

(12) A: So I heard some really bad things about John.

B: ?\#Yeah, threw away Mary's present yesterday.

This suggests that (11B) does involve fragment answer ellipsis. ${ }^{11}$ Note further that fragments do need to be syntactic constituents: it is not simply possible to delete just any 'backgrounded' material, leaving behind a non-constituent fragment:

(13) A: What happened to John?
a. B: \#Mary attacked.
b. B: \#Mary leapt on.
c. B: \#Mary gave a present.

It seems that we must acknowledge the possibility of finite VP constituents, contrary to the prediction made by O-DG. How can we account for the fact that this putative constituent does not pass the remaining constituency tests? This is a topic of ongoing debate (see, e.g., Harwood 2015 and references cited there), but I am not aware of a better alternative than simply stipulating a particular 'cut-off point', which in Harwood's analysis corresponds to the notion of 'phase' (Chomsky 2000 et seq.); only phases (or complements of phase heads) can be moved. Regardless of the particular terminology chosen, though, from anyone's point of view there must be certain constituents that can undergo VP-fronting or VP-ellipsis, and others that cannot.

Suppose we adopt the clausal structure in (14) for the sentence The cake must have been being eaten (I abstract away from the structure underlying each auxiliary and its inflectional affix for ease of presentation):

\footnotetext{
${ }^{11}$ Indeed, sometimes a finite VP answer seems better than a non-finite VP answer:

(i) A: What does he do?

B: Works in Asda.

B': ?\# Work in Asda.
} 
$(14)$

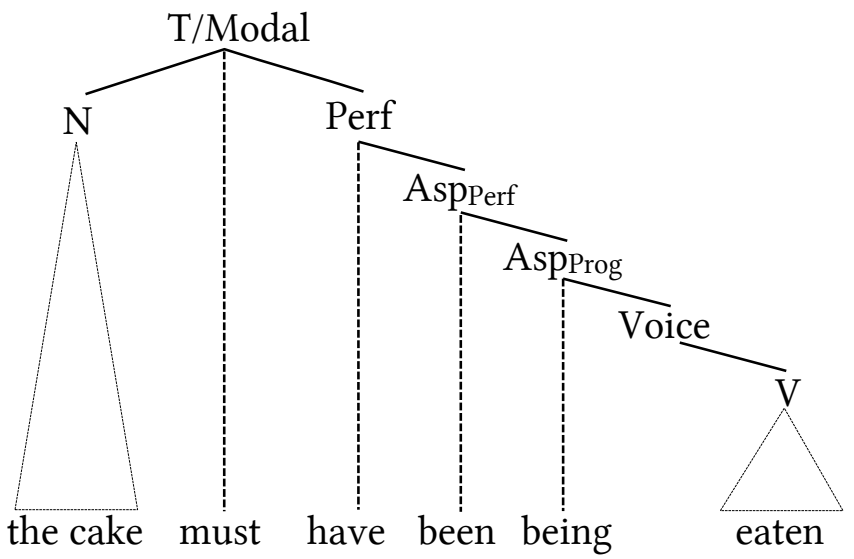

In terms of essential constituent structure, (14) corresponds both to the O-DG and MT analyses of the sentence (see, e.g., Brody 2000a, 2000b, Osborne 2016: section 7.11). ${ }^{12}$ Under both frameworks, then, it is necessary to say something like: only the Aspprog constituent can undergo VP-fronting (cf. Harwood 2015). For VP-ellipsis, the possibilities are wider: any auxiliary-headed constituent can be elided except the topmost, which is as expected given that must have been being eaten does not correspond to a constituent.

The two frameworks can be separated, however, in the case of fragments. Under the O-DG analysis of a sentence containing a tensed main verb, such as (5b), there cannot be a constituent containing only the main verb and the object and excluding the subject, as a matter of principle. Under the MT-type analysis, however, the question of whether there is a 'finite VP constituent' depends on the node in which the verb plus its affix are pronounced, which must be $v$ in English (see section 2). We then have two potential constituents to which grammatical rules may refer: (i) the smallest constituent containing all of the syntactic nodes belonging to the verb, and (ii) the smallest constituent containing the node in which the verb is pronounced. In the tree in (4), (i) is the smallest constituent containing T, $v$ and $\mathrm{V}$ (i.e., the whole tree), while (ii) is the smallest constituent containing $v$ (the node where the inflected verb is pronounced). We can then say that rules such as VP-fronting and VP-ellipsis refer to constituents in the sense of (i), while fragment answers refer to constituents in the sense of (ii), and are hence more permissive than the other rules.

One advantage of the relative structural flexibility of MT, then, is that it can express the differences between fragment answers and other constituency tests in a simple way. By contrast, it is difficult to see how O-DG could handle these differences, as there is only one syntactic (i.e., hierarchical) 'position' for any given finite verb.

12 The analysis in (14) is also somewhat similar to the Minimalist analysis of Bjorkman (2011), who argues that auxiliary be does not constitute a separate node from its affix, but is inserted as a 'last resort' to provide an attachment site for the affix. She further assumes (for reasons of adverb placement, etc.) that the main verb in English is always spelled out (with its suffix) in the V position. Although I refer to (14) as essentially corresponding to an MT analysis, it is not quite equivalent to the MT structures proposed by Brody (2000a, 2000b) for auxiliary sequences. As noted in section 1, Brody argues that the head-complement relation only holds between a verbal root and its inflectional suffix(es), with dependencies between independent words always being expressed as specifier-head relations. Thus, in (14), for example, the Voice node (corresponding to the -en affix ultimately spelled out in the position of the verb) would be the specifier of passive be, not its complement. My reason for choosing (14) is ease of presentation, and this choice does not affect the argument being made here. 


\section{Ordering and scope}

In this section, I will argue that the relaxation of the 1:1 word-node ratio in MT (as in PSGs) allows it to account more straightforwardly than O-DG for the ordering and interpretation of adverbials with respect to verbal elements.

O-DG differs from both standard Minimalism and MT in that a clause with no auxiliary lacks an auxiliary ( $\mathrm{T}$ ) node. One very influential argument for positing a T node relates to crosslinguistic differences in the ordering of verbs and adverbs. For instance, it is generally assumed within Minimalism that the finite verb remains within the VP (or perhaps $v \mathrm{P}$ ) in English, but 'moves to T' in French. If adverbs such as often appear in the same position in both languages (e.g., adjoined to $v \mathrm{P}$ ), this accounts for the fact that the neutral ordering of the verb is after the adverb in English, but before it in French (see esp. Emonds 1978, Pollock 1989, Cinque 1999):

(15) a. Bill often kisses John.
b. Guillaume embrasse souvent Jean. Guillaume kisses often Jean

a'. *Bill kisses often John.

b'. *Guillaume souvent embrasse Jean. Guillaume often kisses Jean

MT eschews movement in this case, instead requiring the verb, together with its affix(es), to be spelled out in a particular verbal node, the identity of which may vary from language to language ( $v$ in English, T in French).

Under an O-DG analysis, the differences in (15) cannot be captured in terms of the hierarchical structure of the sentences. Rather, linearisation rules must be provided, saying simply 'adverbs must precede the finite verb' in English and 'adverbs must follow the finite verb' in French. ${ }^{13}$ Given the lack of apparent independent motivation for V-to-T movement, or spell-out in $\mathrm{T}$ rather than in $\mathrm{V}$, one might concede that there is no particular advantage to stating the restriction hierarchically in this case, as opposed to stating it purely linearly. When more facts are considered, however, it becomes clear that a purely linear account results in considerable complications.

First, consider the fact that adverbials in English tend to show 'mirror image' effects, in that the natural order of two given adverbs when they appear before the verb is normally the opposite of that when they appear after the verb and its objects (e.g., Andrews 1983, Quirk et al. 1985, Ernst 1994, 2002, Pesetsky 1989, 1995)::14,15

(16) a. Tom has already completely ruined dinner.

a'. *Tom has completely already ruined dinner.

${ }^{13}$ Ordering statements will also be needed for auxiliaries with respect to adverbs, indicating their neutral position:

(i) a. Bill has often kissed John. a'. Bill often has kissed John. [ok only if has is stressed]

${ }_{14}$ The judgements in (16) assume that the sentence corresponds to a single intonational phrase, with no 'comma' intonation around the adverbs. For instance, (i) seems acceptable, with generally treated as a parenthetical:

(i) Tom has already, generally, done his homework by the time we get home.

${ }^{15}$ As Phillips (2003: section 4.5) discusses in detail, left-to-right scope is sometimes possible with post-verbal adverbials if the final adverbial is focused (see also Haider 2004: 795-796, Larson 2004, Bobaljik 2017, Neeleman \& Payne 2017). The important point for the in-text discussion is the availability of right-to-left scope, not the additional possibility of left-to-right scope. 
b. Tom has ruined dinner completely already.

b'. *Tom has ruined dinner already completely.

A simple way of capturing this order, under a Minimalist/PSG approach, is to represent the verb phrase as a 'nested' structure, with each adverb being interpreted as modifying (taking scope over) its sister node in the tree. Under this approach, (16a) would have the constituent structure in (17a), in which the adverb completely takes the verb phrase ruined dinner (i.e., the node marked C) as its sister, and already attaches to the resulting constituent (i.e., the node marked B) to form the node marked A, also a verb phrase. (16b), in which the adverbs appear after the minimal verb phrase, and in the opposite order to that in (16a), then involves exactly the same hierarchical structure, but with the linear order of the adverb and its sister node reversed, as in (17b):

(17) a.

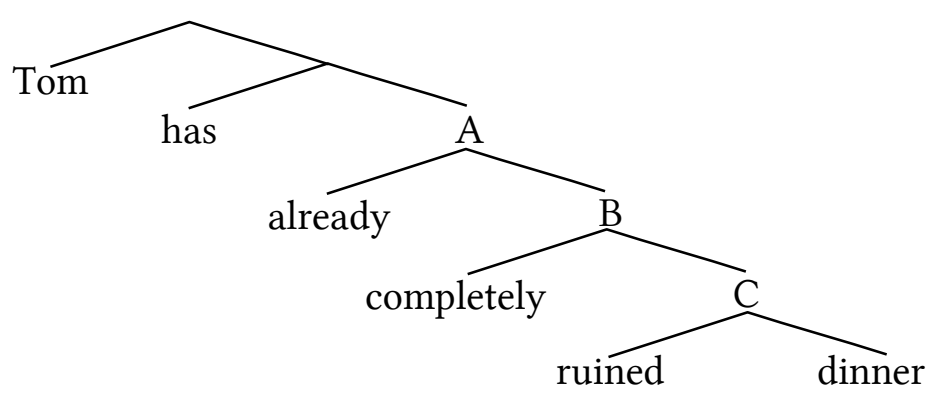

b.

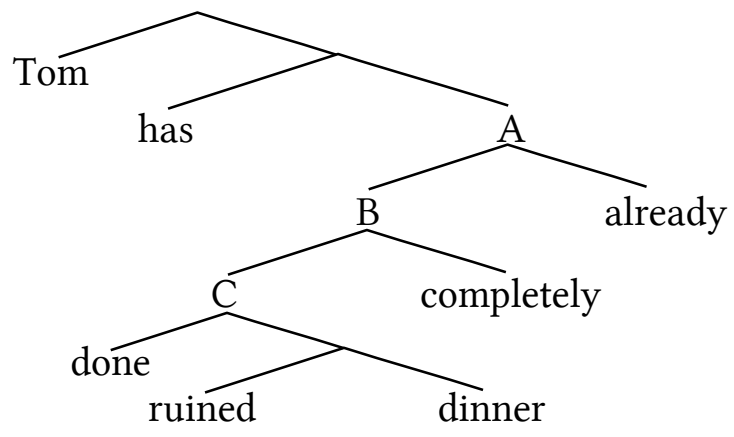

These structures also have the immediate advantage that they naturally express the semantic 'scope' relations between the adverbs. For example, $(16 \mathrm{a}, \mathrm{b})$ both mean that what is already the case is 'John has completely ruined dinner', and not that what has happened completely is 'John has already ruined dinner'. That is, there is a correspondence between the relative positions of the adverbs and their semantic scope. In the structures in (17), this is straightforwardly expressed hierarchically: in both trees, already takes semantic scope over its sister, the node marked B, which includes completely, whereas completely takes scope over its sister, node C, which does not include already.

Under an O-DG analysis, this fact cannot be expressed purely hierarchically, but must make reference only to the linear order of the adverbs with respect to each other and to the verb. For example, one might generalise over $(16 a, b)$ by stating that each adverb takes scope over the rest of the V-headed constituent between it and the verb. Given the natural semantic scope relation already > completely, this would force already to precede completely in (16a) but follow it in (16b). But now consider that in at least some Romance languages, when more than one adverb 
intervenes between the verb and the object, the scope order is left-to-right, as with preverbal adverbs in English (Italian examples in (18) from Cinque 1999: 207):16

(18) a. Gianni vede $\{$ di solito $\}$ \{sempre\} \{raramente\} i suoi parenti. Gianni sees usually always rarely the his relatives 'Gianni \{usually\} \{always\} \{rarely\} sees his relatives.'

b. *Gianni vede $\{$ sempre\} \{di solito\} \{raramente\} i suoi parenti. Gianni sees always usually rarely the his relatives 'Gianni \{always\} \{usually\} \{rarely\} sees his relatives.'

c. *Gianni vede \{di solito\} \{raramente\} \{sempre\} i suoi parenti. Gianni sees usually rarely always the his relatives 'Gianni \{usually\} \{rarely\} \{always\} sees his relatives.'

Thus, the linearisation statements about (16) will not extend to (18), and a different statement is needed for this case. By contrast, under a Minimalist or an MT approach, the same underlying hierarchical positions are assumed in all cases. ${ }^{17}$ The differences between English and Italian are then captured as follows. In English, the finite verb is pronounced in $v$, and there is a choice of locating the adverbs before or after $v(\mathrm{P})$, as in (17). In Italian (as in French), the finite verb is pronounced in $\mathrm{T}$, and adverbs are located before $v(\mathrm{P})$, so adverbs appear between the verb and its object, with left-to-right scope.

A further weakness of the linearisation approach is that it is unprincipled; there is no theoretical motivation for referring to the linear position of the verb, as opposed to just the positions of the adverbs alone. This means that it makes no predictions about possible scope relations cross-linguistically; for example, we might expect that some languages make reference to the position of the verb and others do not, with no correlation between this choice and other aspects of the grammar. By contrast, the postulation of a consistent hierarchical ordering of adverbs, plus the possibility of verb-movement to higher positions, leads us to expect, for example, that there should be no languages in which verb and object can be linearly separated by adverbs $(\mathrm{V}>\mathrm{Adv} 1>\mathrm{Adv} 2>\mathrm{O})$ but such adverbs take right-to-left scope (e.g., Adv2 taking scope over Adv1 in the preceding example). While I am unaware of work that specifically examines this prediction, I have also been unable to find evidence in the literature of such a language (cf. Nilsen 2003: 30). If correct, this supports the hierarchical approach over an O-DG approach, as there is no reason in the latter why a linearisation rule could not say something like 'an adverb takes scope over everything between it and the finite verb' when the adverb appears between verb and object.

${ }^{16}$ Although Cinque (1999) presents the examples with all three adverbs simultaneously, the intended meaning is difficult to access. I use curly brackets to indicate that when any two of the three adverbs appear, they combine in that order. (This is to distinguish the situation from that indicated by round brackets, which would indicate that in (18b-c) the sentence would be bad even if none of the adverbs were present, which is of course not the case.)

17 The assumption I am making here is that a theory of grammar should aim to characterise Universal Grammar - the structural rules underlying human language in general - rather than concerning itself only with the grammar of a single language. (Probably the most famous statement of this aim can be found in chapter 1 of Chomsky 1965.) From a methodological point of view, if one notices the same or similar phenomena arising in language after language, it seems to me to be preferable to provide a single explanation for the similarities, in the absence of evidence to the contrary. See Cinque (1999) for a prominent example of this approach applied to adverb ordering in a wide range of languages. 
To summarise, although the number of syntactic nodes in Minimalist and MT structures is larger than that in O-DG structures, Minimalism and MT allow for a simpler relation between syntax (tree structures) on the one hand and semantics (scope) and phonology (word order) on the other. That is, scope is determined in terms of sisterhood in a tree structure, while word order is determined in terms of the specifier-head-complement relations described in section 2.

\section{Conclusion}

I believe that Osborne's critique of phrase structure grammars is justified to the extent that there is no real evidence for the head-phrase distinction (aside, possibly, from the case of adjunction), and that textbook presentations of constituency tests often gloss over the question of whether a particular structure is really supported by a particular test or set of tests. I also believe, however, that some of Osborne's criticisms are overstated, in that they focus on constituency tests to the exclusion of other reasons for positing more complex structures: in particular, linearisation and scope (not to mention binding, secondary predication, control, etc., which would require much more space for adequate discussion). Furthermore, lying behind Osborne's criticisms of the use of constituency tests within PSG is the assumption that such tests are a necessary condition for constituency. As I have shown, this clearly cannot be the case given that even Osborne's dependency grammar structures are not fully supported by constituency tests. I have argued that a Mirror-Theory-type framework is sufficiently restrictive to account naturally for the restrictions on constituency that Osborne identifies, while providing enough flexibility to account for discrepancies among constituency tests, as well as cross-linguistic differences in the ordering of adverbs and verbal elements.

\section{References}

Adger, David. 2003. Core syntax: A Minimalist approach. Oxford University Press.

Adger, David. 2013. A syntax of substance. Cambridge, MA: MIT Press.

Adger, David, Daniel Harbour \& Laurel J. Watkins. 2009. Mirrors and microparameters: Phrase structure beyond free word order. Cambridge: Cambridge University Press.

Andrews, Avery, 1983. A note on the constituent structure of modifiers. Linguistic Inquiry 13, 313-317.

Baker, Mark. 1985. The Mirror Principle and morphosyntactic explanation. Linguistic Inquiry 16, 373415.

Bjorkman, Bronwyn. 2011. BE-ing default: The morphosyntax of auxiliaries. Ph.D. dissertation, MIT. Bobaljik, Jonathan D. 1995. Morphosyntax: The syntax of verbal inflection. Ph.D. dissertation, MIT.

Bobaljik, Jonathan D. 2017. Knocking twice intentionally. In: Claire Halpert, Hadas Kotek \& Coppe van Urk (eds.) A pesky set: Papers for David Pesetsky,. Cambridge, MA: MITWPL.

Brody, Michael. 1994. Phrase structure and dependence. UCL Working Papers in Linguistics 6, 1-33.

Brody, Michael. 2000a. Mirror theory: Syntactic representation in Perfect Syntax. Linguistic Inquiry 31, 29-56.

Brody, Michael. 2000b. Word order, restructuring and Mirror Theory. In: Peter Svenonius (ed.), The derivation of $V O$ and $O V, 27-43$. Amsterdam: John Benjamins

Brody, Michael. 2003. 'Roll-up' structures and morphological words. In: Towards an elegant syntax, 232251. London \& New York: Routledge.

Brody, Michael \& Anna Szabolcsi. 2003. Overt scope in Hungarian. Syntax 6, 19-51.

Bury, Dirk. 2003. Phrase structure and derived heads. Ph.D. dissertation, University College London.

Bury, Dirk \& Hiroyuki Uchida. 2012. Constituent structure sets II. In: Myriam Uribe-Etxebarria \& Vidal Valmala (eds.), Ways of structure building, 19-43. Oxford \& New York: Oxford University Press. 
Chomsky, Noam. 1965. Aspects of the theory of syntax. Cambridge, MA: MIT Press.

Chomsky, Noam. 1970. Remarks on nominalization. In: R. A. Jacobs \& P. S. Rosenbaum (eds.), Readings in English transformational grammar, 184-221. Waltham, MA: Ginn.

Chomsky, Noam. 1981. Lectures on government and binding: The Pisa lectures. Dordrecht: Foris.

Chomsky, Noam. 1995. The Minimalist Program. Cambridge, MA: MIT Press.

Chomsky, Noam. 2000. Minimalist inquiries: The framework. In: Roger Martin, David Michaels \& Juan Uriagereka (eds.), Step by step: Essays on Minimalist syntax in honor of Howard Lasnik, 89-155. Cambridge, MA: MIT Press.

Chomsky, Noam. 2001. Derivation by phase. In: Michael Kenstowicz (ed.), Ken Hale: A Life in Language, 1-52. Cambridge, MA: The MIT Press.

Cinque, Guglielmo. 1999. Adverbs and functional heads. Oxford: Oxford University Press.

Culicover, Peter W. \& Ray Jackendoff. 2006. Simpler syntax. Oxford: Oxford University Press.

Dryer, Matthew S. 2013. Prefixing vs. suffixing in inflectional morphology. In: Matthew S. Dryer \& Martin Haspelmath (eds.), The world atlas of language structures online. Leipzig: Max Planck Institute for Evolutionary Anthropology. (Available online at http://wals.info/chapter/26, Accessed on 2019-06-03.)

Emonds, Joseph. 1978. The verbal complex V'-V in French. Linguistic Inquiry 9, 151-175.

Ernst, Thomas. 1994. M-command and precedence. Linguistic Inquiry 25, 327-335.

Ernst, Thomas. 2002. The syntax of adjuncts. Cambridge: Cambridge University Press.

Haddican, Bill. 2007. The structural deficiency of verbal pro-forms. Linguistic Inquiry 38, 539-547.

Haegeman, Liliane. 1990. Understood subjects in English diaries. Multilingua 9, 157-199.

Haider, Hubert. 2004. Pre- and post-verbal adverbials in OV and VO. Lingua 114, 779-807.

Harwood, William. 2015. Being progressive is just a phase: Celebrating the uniqueness of progressive aspect under a phase-based analysis. Natural Language \& Linguistic Theory 33, 523-573.

Hornstein, Norbert, Jairo Nunes and Kleanthes K. Grohmann. 2005. Understanding Minimalism. Cambridge: Cambridge University Press.

Hudson, Richard. 1990. English Word Grammar. Oxford: Blackwell.

Kayne, Richard S. 1994. The antisymmetry of syntax. Cambridge, MA: MIT Press.

Kratzer, Angelika. 1996. Severing the external argument from its verb. In: Johan Rooryck \& Laurie Zaring (eds.), Phrase structure and the lexicon, 109-137. Dordrecht: Kluwer.

Larson, Richard K. 2004. Sentence final adverbs and 'scope'. In: M. Wolf \& K. Moulton (eds.), Proceedings of NELS 34. Amherst, MA: GLSA.

Manzini, M. Rita. 1995. From Merge and Move to Form Dependency. UCL Working Papers in Linguistics 7, 323-345.

Merchant, Jason. 2004. Fragments and ellipsis. Linguistics and Philosophy 27, 661-738.

Neeleman, Ad \& Amanda Payne. 2017. PP extraposition and the order of adverbials in English. Ms., University College London \& University of Delaware.

Nilsen, Øystein. 2003. Eliminating positions: Syntax and semantics of sentence modification. Ph.D. dissertation, Utrecht University.

Osborne, Timothy. 2016. A dependency grammar of English: An introduction and beyond. Ms., Zhejiang University.

Osborne, Timothy. 2018. Tests for constituents: What they really reveal about the nature of syntactic structure. Language Under Discussion 5(1), 1-41.

Osborne, Timothy \& Thomas Gross. 2016. The do-so-diagnostic: Against finite VPs and for flat non-finite VPs. Folia Linguistica 50: 97-135.

Pesetsky, David. 1989. Language particular processes and the earliness principle. Ms., MIT.

Pesetsky, David. 1995. Zero syntax: Experiencers and cascades. Cambridge, MA: MIT Press.

Phillips, Colin. 2003. Linear order and constituency. Linguistic Inquiry 34, 37-90. 
Pollock, Jean-Yves. 1989. Verb movement, Universal Grammar, and the structure of IP. Linguistic Inquiry $20,365-424$.

Pullum, Geoffrey \& Deirdre Wilson. 1977. Autonomous syntax and the analysis of auxiliaries. Language 53, 741-788.

Quirk, Randolph, Sidney Greenbaum, Geoffrey Leech \& Jan Svartvik. 1985. A comprehensive grammar of the English language. London: Longman.

Reeve, Matthew. 2019. An agreement-based analysis of extraction from nominals. Natural Language \& Linguistic Theory 37, 263-314.

Svenonius, Peter. 2016. Spans and words. In: Daniel Siddiqi (ed.), Morphological metatheory, 201-222. Amsterdam: John Benjamins.

Uchida, Hiroyuki \& Dirk Bury. 2008. Constituent structure sets. UCL Working Papers in Linguistics 20, 87-111. 